\author{
Marquette University \\ e-Publications@Marquette
}

College of Nursing Faculty Research and

Publications

Nursing, College of

$9-2013$

\title{
Psychometric Assessment of the Depressive Cognition Scale in Caregivers of Persons with Dementia
}

\author{
Abir K. Bekhet \\ Marquette University, abir.bekhet@marquette.edu \\ Jaclene Zauszniewski \\ Case Western Reserve University
}

Follow this and additional works at: https://epublications.marquette.edu/nursing_fac

Part of the Nursing Commons

\section{Recommended Citation}

Bekhet, Abir K. and Zauszniewski, Jaclene, "Psychometric Assessment of the Depressive Cognition Scale in Caregivers of Persons with Dementia" (2013). College of Nursing Faculty Research and Publications. 305.

https://epublications.marquette.edu/nursing_fac/305 


\title{
Marquette University
}

\section{e-Publications@Marquette}

\section{Faculty Research and Publications/College of}

This paper is NOT THE PUBLISHED VERSION; but the author's final, peer-reviewed manuscript. The published version may be accessed by following the link in the citation below.

Issues in Mental Health Nursing, Vol. 34, No. 9 (2013): 678-684. DOI. This article is (C) Taylor \& Francis and permission has been granted for this version to appear in e-Publications@Marquette. Taylor \& Francis does not grant permission for this article to be further copied/distributed or hosted elsewhere without the express permission from Taylor \& Francis.

\section{Psychometric Assessment of the Depressive Cognition Scale in Caregivers of Persons with Dementia}

\author{
Abir K. Bekhet \\ College of Nursing, Marquette University, Milwaukee, WI \\ Jaclene A. Zauszniewski \\ Bolton School of Nursing, Case Western Reserve University, Cleveland, $\mathrm{OH}$
}

\section{Abstract}

Caregivers of persons with dementia are prone to depression. Early identification of cognitive depressive symptoms is important to prevent the development of clinical depression. The Depressive Cognition Scale (DCS) can be used for early detection, but the scale's psychometrics have not been tested in caregivers of persons with dementia. In this study, 80 caregivers of persons with dementia completed the eight-item DCS and measures of caregiver burden and resourcefulness. A Cronbach's alpha of .88 indicated internal consistency. Construct validity was supported by significant correlations with caregiver burden $(r=.40 ; p<.001)$ and resourcefulness $(r=-.54 ; p<.001)$. Principal components factor analysis resulted in two factors in which five items loaded cleanly on one factor and two items 
have cross-loadings. Because prior factor analysis in previous studies resulted in one factor, we did confirmatory factor analysis in which we forced the items on one factor. All the items loaded on the single factor and the amount of variance explained was $55.99 \%$. The findings suggest the DCS is useful for early detection of depression in caregivers of persons with dementia.

By the year 2050, the number of American people diagnosed with dementia is expected to rise to as many as 16 million; triple the current number of 5.4 million (Alzheimer's Association, 2012). Recent statistics indicate that $80 \%$ of the care these persons need is provided at home by family members who assume the role of informal caregivers (Alzheimer's Association, 2012). Dementia caregivers, however, are at high risk for developing physical and psychological health problems (Cucciare, Gray, Azar, Jimenez, Gallagher-Thompson, 2010; Pinquart \& Sorensen, 2004). In fact, previous research has indicated that informal or unpaid dementia caregivers experience a high rate of clinical depression (Caspar \& O'Rourke, 2009; Fisher et al., 2011; Flynn Longmire \& Knight, 2010; Tremont, 2011): Approximately half of caregivers of persons with dementia meet the diagnostic criteria for clinical depression (Ballard, Eastwood, Gahir, \& Wilcock, 1996; Cuijpers, 2005). Other research has found that spouses of persons with dementia have a four time higher risk of developing depression than spouses of persons without dementia (Joling et al., 2010).

Depression interferes with personal and social functioning, causes suffering, and plays a major factor in the development of chronic medical conditions (Katon, 2003; Pratt \& Brody, 2008; Steptoe, 2007). The economic cost of depressive diseases in the US is estimated to be $\$ 83$ billion for medical expenditures, loss of work productivity, and suicide related costs (Greenberg et al., 2003).

Without a doubt, culture plays an essential role in shaping the caregivers' experiences, which can be vastly different among various ethnic backgrounds (Adams, Aranda, Kemp, \& Takagi, 2002; Etters, Goodall, \& Harrison, 2008). Studies have shown that Caucasian caregivers report lower life satisfaction than their African American counterparts (Lawton, Rajagopal, Brody, \& Kleban, 1992). Also, Caucasian caregivers report more depression than African American caregivers (Etters et al., 2008; Janevic \& Connell, 2001).

\section{PREVIOUS MEASURES OF DEPRESSION}

Previous studies have used various scales to measure depression among caregivers of persons with dementia. The Center for Epidemiological Studies Depression Scale (CES-D; Radloff 1977) is widely used to assess depressive symptoms among caregivers of persons with dementia (Caspar \& O'Rourke, 2009; Cucciare et al., 2010; Flynn Longmire \& Knight, 2010; Haley et al., 2004; Wang, Shyu, Chen, \& Yang, 2011; Wong et al., 2008). Some research, however, has used the 21-item Beck Depression Inventory (BDI; Beck, Ward, Mendelson, Mock, \& Erbaugh, 1961; Välimäki, Vehviläinen-Julkunen, Pietilä, \& Pirttilä, 2009; Watson, Lewis, Moore, \& Jeste, 2011) and the 15-item Geriatric Depression Scale (GDS; Sheikh \& Yesagave, 1986) to measure depression among dementia caregivers (Covinsky et al., 2003; Gaugler, Mittelman, Hepburn, \& Newcomer, 2010; Rosness, Mjørud, \& Engedal, 2011). 
Although these scales are widely used among caregivers of persons with dementia and they are reliable and valid, they all measure symptoms reflecting clinical depression; none of the scales measure the cognitive symptoms that may precede and predict clinical depression.

According to Beck's cognitive theory of depression, cognitive symptoms appear earlier than affective, motivational, and somatic symptoms of depression (Beck, 1991). More specifically, Beck's theory suggests that negative views toward the self, world, and future, which he labeled the "negative cognitive triad," precede the development of clinical depression. Consequently, for early detection and prevention of clinical depression, there is a compelling need to assess depressive cognitions among caregivers of persons with dementia. It is vital to have a reliable and a valid scale to assess these cognitive symptoms before the development of clinical depression.

\section{THE CONCEPTUAL BASIS OF THE DEPRESSIVE COGNITION SCALE}

The Depressive Cognition Scale (DCS), originally developed by Zauszniewski (1995), measures eight depressive cognitions that precede clinical depression. The scale is based on Beck's negative cognitive triad, which postulates that negative cognitions precede clinical depression (Beck, 1991). Beck's triad of negative views of self, the world, and the future, were later re-conceptualized by Zauszniewski (1995) as worthlessness, powerlessness, and hopelessness. The remaining five depressive cognitions on the scales-helplessness, purposelessness, loneliness, emptiness, and meaninglessness-stem from Erikson's psychosocial stages of development and reflect unsuccessful resolution of any of the stages (Erikson, 1994; Zauszniewski, 1995); thus, when scoring is reversed, the DCS measures depressive cognitions.

The DCS has been used widely with different populations, including older adults, African-American women, caregivers of persons with autism, and caregivers of persons with serious mental illness (Bekhet, Johnson, \& Zauszniewski, 2012; Bekhet, Zauszniewski, \& Wykle, 2008; Zauszniewski, 1995, 1997; Zauszniewski, Picot, Debanne, Wykle, \& Roberts, 2002; Zauszniewski \& Suresky, 2010). One prior study has tested the psychometric properties of the DCS among caregivers of persons with dementia; however, the sample was restricted to African American women (Zauszniewski et al., 2002). Previous research has indicated that Caucasian caregivers report higher levels of clinical depression than their African American counterparts (Farran, Miller, Kaufman, \& Davis, 1997; Haley et al., 1995, 1996) and culture plays a major role in shaping caregivers' experience. Thus there is an urgent need to assess the psychometric properties of the DCS with a range of caregivers. This study therefore measured the psychometric properties of the Depressive Cognition Scale among Caucasian and African American caregivers of persons with dementia.

\section{METHODS}

\section{Design}

This psychometric study was part of a larger descriptive, correlational, and cross-sectional study. The primary study investigated the moderating role of positive cognitions on the relationship between caregiver burden and resourcefulness. Results indicated that positive cognitions acted as a moderator in attenuating the effects of caregiver burden on resourcefulness (Bekhet, 2012). The sample in the 
parent study included 80 male and female caregivers of persons with dementia. No participants were excluded on the basis of gender, race, or socio-economic status.

\section{Procedure}

After approval was obtained from the Institutional Review Board in the parent study, participants were recruited from Alzheimer's Association early stage programs in Southeastern Wisconsin. Those who were interested contacted a research assistant and an agreed-upon meeting date and time was determined. At that meeting, participants completed a consent form and the study questionnaires. Descriptive data on the caregivers were collected and in addition to the Depressive Cognition Scale, participants completed measures that are theoretically related to depressive cognitions, namely, caregiver burden and resourcefulness, to test the construct validity of the Depressive Cognition Scale (DCS). After completing the questionnaires, caregivers were given a \$15 gift card.

\section{Instruments}

Depressive cognitions were measured by the Depressive Cognition Scale (DCS). The DCS consists of eight items responded to in a 6-point Likert scale ranging from strongly agree (5) to strongly disagree (0) (Zauszniewski, 1995). All eight items are phrased positively (Zauszniewski, Chung, Krafcik, \& Sousa, 2001); thus the scale measures depressive cognitions when the items are reverse coded. Scores range from 0-40 and, after reverse coding the eight items, the higher the scores, the higher the depressive cognitions (Zauszniewski, 1997). Previous research has demonstrated that the DCS has acceptable reliability and validity. Acceptable reliability was evidenced by reported alphas of .84 in older adults (Bekhet et al., 2008) and .90 in caregivers of persons with autism (Bekhet et al., 2012). Construct validity was supported by significant correlations in the expected direction with measures of psychosocial development, adaptive functioning, and resourcefulness $(r=-.63 ; p<.001 ; r=-.60 ; p<$ $.001, r=-.57 ; p<.01$ ) in older adults (Bekhet \& Zauszniewski, 2013; Zauszniewski 1995, 1997); and with measures of resourcefulness $(r=-.53)$ in women with diabetes $(r=-.53 ; p<.001)$ (Zauszniewski et al., 2001). A single factor resulting from a confirmatory factor analysis explained $40 \%$ of the total variance, with all item factor loadings exceeding .30 (Zauszniewski, 1997; Zauszniewski et al., 2001). Examples of the scale items include: "I am hopeful about my future," "I have many people in my life," and "I am a worthwhile human being."

Caregiver burden was measured by the Zarit Burden Interview (ZBI; Zarit, Reever, \& Bach-Peterson, 1980). The 22-item version was used in this study (Knight, Fox, \& Chou, 2000). ZBI items are rated on a 5-point Likert type scale; scores range from 0-88, and the higher the score, the greater the level of burden. The ZBI has internal consistency estimates ranging from Cronbach's alpha = .88 to .92 (Chou, Chu, Tseng, \& Lu, 2003; Thompson, Futterman, Gallagher-Thompson, Rose, \& Lovett, 1993). Cronbach's alpha in this study was .93. Examples of the scale items are: "Do you feel that your relative asks for more help than he/she needs?" and "Do you feel stressed between caring for your relative and trying to meet other responsibilities for your family or work?"

Resourcefulness was measured by the 28-item Resourcefulness Scale (RS; Zauszniewski, Lai, \& Tithiphumturong, 2006), which assesses two aspects of resourcefulness, personal (self-help) and social (help-seeking) (Zauszniewski et al., 2006). Items on the Resourcefulness Scale are rated on a 6-point Likert scale and scores range from 0-140, with higher scores reflecting greater personal and social 
resourcefulness (Zauszniewski et al., 2006). The scale is reliable, as evidenced by internal consistency estimates of $.83, .79$, and .85 for the total scale and for the personal and social resourcefulness subscales, respectively (Zauszniewski et al., 2006). Construct validity was indicated by the emergence of two dimensions of resourcefulness (personal and social) in a confirmatory factor analysis, and by substantial inter-correlations between the two subscales $(r=.41, p<.001)$ (Zauszniewski et al., 2006). Cronbach's alpha in this study was .92. Examples of the scale items are: "When I do a boring job, I think about the less boring parts of the job and the reward I will receive once I am finished," and "When I have something to do that is anxiety arousing for me, I try to visualize how I will overcome my anxiety while doing it."

\section{Psychometric Analysis}

Psychometric testing of the DCS measure included estimating reliability and construct validity. Data were analyzed using IBM SPSS Statistics 19.0. Descriptive statistics, such as means and standard deviations, as well as frequency distributions, were examined. Reliability analyses involved examination of Cronbach's alphas, inter-item correlations, and item-to-total scale correlations. Reliability was determined by the following criteria: (1) the acceptable internal consistency exceeded .70 (Ferketich, 1991; Nunnally \& Bernstein, 1994); (2) A substantial number of the scale items had corrected item-to-total scale correlations between .30 and .70, indicating the homogeneity of the scale (Ferketich, 1991); and (3) The inter-item correlations fell between .30 and .70 (Nunnally \& Bernstein, 1994).

Construct validity was examined through factor analysis and correlations in the expected direction with measures of theoretically related constructs, namely burden and resourcefulness.

\section{RESULTS}

The mean age of the 80 caregivers in the study was 57.5 years, and their ages ranged from 22 to 87 years. Seventy-two were females, representing $90 \%$ of the sample. Over half of the caregivers $(56.3 \%)$ were Caucasian; 35\% were African American $(n=28)$ and the remainder were Hispanic, Asian, or identified as Other. A detailed description of the study has been reported elsewhere (Bekhet, 2012). Table 1 displays the means, standard deviations, possible ranges, and actual ranges on measures of depressive cognitions, caregiver burden, and resourcefulness.

TABLE 1 Descriptive Statistics for Depressive Cognition Scale and Construct Validation Measures in Caregivers of Persons with Dementia $(N=80)$

\begin{tabular}{|l|l|l|l|l|}
\hline Validating & Mean & Actual & Possible & Cronbach's \\
\hline Construct & $(S D)$ & Range & Range & Alpha \\
\hline Depressive Cognitions & $4.9(5.2)$ & $0-27$ & $0-40$ & .88 \\
\hline Caregiver Burden & $35.4(17.0)$ & $0-78$ & $0-88$ & .93 \\
\hline Resourcefulness & $101.0(18.8)$ & $36-136$ & $0-140$ & .92 \\
\hline
\end{tabular}

\section{Reliability}

The overall internal consistency of the DCS was Cronbach's alpha $=.88$, indicating acceptable internal consistency since it exceeds the minimum criterion of .70 for a new measure and .80 for an established 
measure (Ferketich, 1991; Nunnally \& Bernstein, 1994). Deletion of any one of the items would not improve the scale's internal consistency (Table 2).

TABLE 2 The Depressive Cognition Scale Item Analysis and Factor Analysis

\begin{tabular}{|l|l|l|}
\hline DCS & Alpha if & Item-to-Total \\
\hline Item & Item Deleted & Score Correlations \\
\hline Emptiness & .854 & .602 \\
\hline Helplessness & .872 & .398 \\
\hline Hopelessness & .840 & .711 \\
\hline Loneliness & .853 & .606 \\
\hline Meaninglessness & .840 & .746 \\
\hline Powerlessness & .858 & .575 \\
\hline Purposelessness & .832 & .804 \\
\hline Worthlessness & .855 & .652 \\
\hline
\end{tabular}

TABLE 3 Inter-Item Correlation among the Eight DCS Items in Family Caregivers of Persons with Dementia $(N=80)$

\begin{tabular}{|l|l|l|l|l|l|l|l|l|}
\hline DCS Item & 1 & 2 & 3 & 4 & 5 & 6 & 7 & 8 \\
\hline 1. Emptiness & & .290 & .586 & .422 & .499 & .352 & .597 & .365 \\
\hline 2. Helplessness & & & .597 & .199 & .286 & .186 & .239 & .351 \\
\hline 3. Hopelessness & & & & .517 & .507 & .411 & .545 & .452 \\
\hline 4. Loneliness & & & & & .467 & .549 & .565 & .365 \\
\hline 5. Meaninglessness & & & & & & .483 & .869 & .821 \\
\hline 6. Powerlessness & & & & & & & .597 & .429 \\
\hline 7. Purposelessness & & & & & & & & .681 \\
\hline 8. Worthlessness & & & & & & & & 1 \\
\hline
\end{tabular}

Regarding the homogeneity of a scale, $63 \%$ of the scale items had item-to-total scale correlations within the recommended range, while the other $27 \%$ exceeded the acceptable range. The items that exceeded the acceptable range reflected hopelessness, meaninglessness, and purposelessness (Table 2).

Nunnally and Bernstein (1994) suggested that inter-item correlations should fall between .30 and .70, and values greater than .70 indicate item redundancy. Applying these criteria, $75 \%$ of the possible 28 inter-item correlations fell between $r=.30$ and $r=.70$. Two items were above the recommended value of .70, and 5 inter-item correlations fell below the recommended criteria (Table 3), perhaps reflecting the characteristics of the dementia caregivers (Nunnally \& Bernstein, 1994).

\section{Dimensionality and Construct Validity}

Based on the recommended criteria of 5-10 participants per item, the sample of 80 caregivers of persons with dementia was adequate to conduct factor analysis of the 8-item DCS (Hair, Anderson, Tatham, \& Black, 1998). The Kaiser-Meyer-Olkin (KMO) value was also checked to determine the sample's adequacy for factor analysis. A value of at least .60 is required (Tabachnick \& Fidell, 2001), and in this study the KMO value was .80 , indicating that the sample size was adequate for factor 
analysis. Also, Bartlett's test of sphericity was significant $\left(x^{2}=386.55 ; p<.001\right.$; determinant $\left.=.006\right)$, indicating that the correlation matrix was appropriate for factor analysis (Strickland, 2003). Principal components factor analysis was conducted on the 8-item DCS to extract the minimum number of factors that explained the maximum variance in scale items. The extraction resulted in two factors; six items loaded cleanly on one factor, and two items had cross-loadings (Table 4). Prior factor analysis had resulted in one factor (Bekhet \& Zauszniewski, 2013; Zauszniewski 1995, 1997), therefore, we also did a confirmatory factor analysis in which we forced the items on one factor. All the items loaded on the single factor (Table 4), but the amount of variance explained was $55.99 \%$, which was less than the amount of variance explained with the two factor solution (68.44\%). Construct validity of the DCS was supported by significant positive correlations with measures of burden $(r=.40 ; p<.001)$ and significant negative correlations with measures of resourcefulness $(r=-.54 ; p<.001)$, indicating that higher caregiver burden was associated with greater depressive cognitions, and higher levels of resourcefulness were associated with fewer depressive cognitions.

\section{TABLE 4 Confirmatory Factor Analysis of DCS: One and Two Factor Solutions}

\begin{tabular}{|l|l|l|l|}
\hline DCS & One Factor Solution & Two Factor & Solution \\
\hline Item & Factor Loadings & Factor & Loadings \\
\hline Emptiness & .697 & .692 & - \\
\hline Helplessness & .488 & .488 & .774 \\
\hline Hopelessness & .768 & .768 & .461 \\
\hline Loneliness & .692 & .692 & - \\
\hline Meaninglessness & .865 & .865 & - \\
\hline Powerlessness & .681 & .681 & - \\
\hline Purposelessness & .891 & .891 & - \\
\hline Worthlessness & .775 & .775 & - \\
\hline
\end{tabular}

\section{DISCUSSION}

This psychometric analysis of the Depressive Cognition Scale (Zauszniewski, 1995) provides further evidence of the measure's internal consistency reliability and construct validity with caregivers of persons with dementia. Though the psychometric properties of the scale were reported in a previous study of dementia caregivers (Zauszniewski et al., 2002), the caregivers in this study were more diverse in race and ethnicity and both men and women caregivers were included; the earlier study targeted only African American women caregivers of persons with dementia. The internal consistency estimate (alpha $=.88$ ) found in the study reported here was higher than that reported in the study of African American women caregivers (alpha $=.75$ ) (Zauszniewski et al., 2002).

Although the DCS was designed initially to capture depressive thinking patterns that may result from less than successful resolution of developmental stages across the life span, making it most suited to elders who have had greater life experiences (Zauszniewski, 1995), the measure has been found reliable and valid in persons of younger ages, as in this study where ages ranged from 22 to 87 years and the average age was about 58 years.

Similar to other studies of caregivers, homogeneity of the DCS was found in this study of caregivers of persons with dementia, with five of the eight DCS items correlated with the total scale within the 
prescribed range, between .30 and .70 (Ferketich, 1991); the three items that exceeded the recommended range measured hopelessness, meaninglessness, and purposelessness, and the latter was the most prominent with an item-to-total scale correlation of .80. These findings are somewhat similar to those of the study of African American women caregivers of elders with dementia (Zauszniewski et al., 2002), although the items measuring meaninglessness and purposelessness in that study had item-to-total scale correlations that fell in the acceptable range (Zauszniewski et al., 2002). Our findings are consistent with descriptions in the literature of the sense of meaninglessness experienced by caregivers in relation to their care recipient's dementia, particularly when the care recipient is in the later stages of the disease (Albinsson \& Strang, 2003). However, neither the study reported here nor the study of African American women caregivers (Zauszniewski et al., 2002) explored the effects of the length of caregiving or the stage of dementia of the care recipient in relation to the DCS. Further research might explore whether dementia stage is associated with the meaninglessness reported by family caregivers.

The findings on the item capturing purposelessness, which had high item-to-total scale correlations and emerged with the highest factor loading (.89) in the study reported here and in the study of African American women caregivers (.84) (Zauszniewski et al., 2002), suggest that for the dementia caregivers, the DCS scale is highly reflective of feeling useful and needed. Consistent with these findings, other researchers have found that family caregivers, particularly women, report an increased sense of purpose in life associated with caregiving of elders (Cheng et al., 2012; Marks, Lambert, \& Choi, 2002; Teschendorf, Schwartz, Ferrans, O'Mara, Novotny, \& Sloan, 2007.

In this psychometric study, the exploratory factor analysis returned a two-factor solution in which two of the eight items had substantial cross-loadings on both factors, suggesting the presence of a second factor that may differ conceptually from the other six depressive cognitions. Interestingly, these same items, along with loneliness, comprised a clean second factor (with no cross-loadings) in the study of African American women caregivers (Zauszniewski et al., 2002). Although the homogeneity of the sample may have contributed to the clean second factor in that earlier study (Zauszniewski et al., 2002), the emergence of hopelessness and helplessness in both studies of dementia caregivers seems beyond mere coincidence. In fact, helplessness and hopelessness have been identified as key indicators of compassion fatigue, a concept that has been recently applied to informal caregivers, including family members of persons with dementia (Day \& Anderson, 2011).

Factor analytic investigations of the DCS in non-caregiver samples (Zauszniewski, 1995, 1997; Zauszniewski et al., 2001, 2002) and in younger samples of family caregivers (Bekhet et al., 2013; Zauszniewski \& Suresky, 2010) have consistently revealed a single-factor solution in which items reflecting all eight depressive cognitions coalesced; further, the two factors that emerged during the exploratory factor analysis in this study were not clean, that is, there were a number of substantial cross-loadings, therefore, the eight items were forced onto a single factor to confirm the scale's factor structure and construct validity. Interestingly, the two most prominent negative cognitions, that is, those with the highest factor loadings, meaninglessness, and purposelessness, were similar to those that loaded highest in the African American women caregiver study (Zauszniewski et al., 2002) despite the fact that the sample in that study was more homogeneous. 
Finally, construct validity of the DCS was supported in the study reported here by significant correlations in the expected directions with two theoretically related constructs, resourcefulness and caregiver burden. These findings are similar to findings reported in studies of African American women caregivers (Zauszniewski et al., 2002), women family members of persons with serious mental illness (Zauszniewski \& Suresky, 2010), and family members of persons with autism spectrum disorder (Bekhet \& Zauszniewski, 2013).

This psychometric study of the DCS in family caregivers of persons with dementia provides further evidence of the measure's reliability and validity. Since depressive cognitions are believed to appear before other, more serious, symptoms of depression (Beck, 1987), the measure can be useful for screening for depression. In a recent study, a cut score of 7 on the DCS was identified as the point at which interventions to strengthen positive thinking may be beneficial in order to prevent depression (Zauszniewski \& Bekhet, 2012). Examination of the usefulness of this cut score for family members of persons with dementia may help to identify the point at which they could benefit from cognitivebehavioral interventions to strengthen their positive thinking.

\section{Implications for Practice}

The Depressive Cognition Scale has implications for practice. The DCS can be used by nurses and health care professionals to plan for primary prevention strategies to prevent caregivers of persons with dementia from developing depression. Primary prevention is directed toward promoting dementia caregivers' wellness by preventing or decreasing the burden of caregiving, especially those who are at high risk of developing stress and depression. Those could be caregivers who have recently learned about their relatives' diagnosis or who have been dealing with the stress of caregiving over a long period of time. Since depressive cognitions are believed to appear before other, more serious symptoms of depression (Beck, 1987), the measure can be useful for screening for depression.

This 8-item DCS is a brief scale that takes around five minutes to complete. In fact, assessing caregivers' depressive cognitions will help early detection and prevention of depression that might develop as a result of caregiving. The DCS can help health care providers to identify early depressive cognitions that precede clinical depression. In a recent study, a cut score of 7 on the DCS was identified as the point at which interventions to enhance positive thinking may be helpful in preventing the development of depression (Zauszniewski \& Bekhet, 2012). Examples of positive thinking training intervention programs include helping caregivers to use positive self-talk, reframe situations positively, and interrupt negative thoughts by using relaxation techniques.

Intervention programs should also encourage caregivers of persons with dementia to practice using the positive cognitions strategies rather than just knowing them. In fact, previous research indicated that cognitive therapy helped adolescents in terms of lessening their anxieties and depression and improving their self-esteem (Rush \& Beck, 2000). Furthermore, positive cognitive interventions have been found useful in increasing self-efficacy and on lessening negative perceptions (Rush \& Beck, 2000).

Declaration of interest: The authors report no conflicts of interest. The authors alone are responsible for the content and writing of the paper. 


\section{REFERENCES}

Adams, B., Aranda, M. P., Kemp, B., \& Takagi, K. (2002). Ethnic and gender differences in distress among Anglo American, African American, Japanese American, and Mexican American spousal caregivers of persons with dementia. Journal of Clinical Geropsychology, 8, 279-301.

Albinsson, L., \& Strang, P. (2003). Differences in supporting families of dementia patients and cancer patients: A palliative perspective. Palliative Medicine, 17, 359-367.

Alzheimer's Association. (2012). 2012 Alzheimer's Disease Facts and Figures. Retrieved from http://www.alz.org/documents custom/2012 facts figures fact sheet.pdf

Ballard, C. G., Eastwood, C., Gahir, M., \& Wilcock, G. (1996). A follow up study of depression in the carers of dementia sufferers. BMJ, 312, 947.

Beck, A. T. (1987). Cognitive models of depression. Journal of Cognitive Psychotherapy, 1, 5-37.

Beck, A. T. (1991). Cognitive therapy: A 30-year retrospective. American Psychologist, 46(4), 368-375.

Beck, A. T., Ward, C. H., Mendelson, M., Mock, J., \& Erbaugh, J. (1961). An inventory for measuring depression. Archives of General Psychiatry, 4, 561-571.

Bekhet, A. (2012). Effects of positive cognitions and resourcefulness on caregiver burden among caregivers of persons with dementia. International Journal of Mental Health Nursing. doi: 10.1111/j.1447-0349.2012.00877.x

Bekhet, A., Johnson, N., \& Zauszniewski, J. A. (2012). Effects of resilience on caregivers of persons with autism spectrum disorder: The role of positive cognitions. Journal of the American Psychiatric Nurses Association, 18(6), 337-344.

Bekhet, A., \& Zauszniewski, J. A. (2013). Psychometrics of the Depressive Cognition Scale in caregivers of persons with autism spectrum disorders. Archives of Psychiatric Nursing, 27(2), 96-100.

Bekhet, A., Zauszniewski, J. A. \& Wykle, M. (2008). Milieu change and relocation adjustment in elders. Western Journal of Nursing Research, 30(1), 113-129.

Caspar, S., \& O'Rourke, N. (2009). The composition and structure of depressive symptomatology among young and older caregivers of persons with dementia. Ageing International, 34, 33-41.

Cheng, S. T., Lau, R. W., Mak, E. P., Ng, N. S., Lam, L. C., Fung, H. H., Lai, J. C., Kwok, T., \& Lee, D. T. (2012). A benefit-finding intervention for family caregivers of persons with Alzheimer disease: Study protocol of a randomized controlled trial. Trials, 13, 98.

Chou, K. R., Chu, H., Tseng, C. L., \& Lu, R. B. (2003). The measurement of caregiver burden. Journal of Medical Sciences, 23(2), 73-82.

Covinsky, K. E., Newcomer, R., Fox, P., Wood, J., Sands, L., Dane, K., \& Yaffe, K. (2003). Patient and caregiver characteristics associated with depression in caregivers of patients with dementia. Journal of General Internal Medicine, 18(12), 1006-1014.

Cucciare, M., Gray, H., Azar, A., Jimenez, D., \& Gallagher-Thompson, D. (2010). Exploring the relationship between physical health, depressive symptoms, and depression diagnoses in Hispanic dementia caregivers. Aging \& Mental Health, 14(3), 274-282. doi: http://dx.doi.org/10.1080/13607860903483128

Cuijpers, P. (2005). Depressive disorders in caregivers of dementia patients: A systematic review. Aging \& Mental Health, 9(4), 325-330.

Day, J., \& Anderson, R. (2011). Compassion fatigue: An application of the concept to informal caregivers of family members with dementia. Nursing Research and Practice. doi:10.1155/2011/40802

Erikson, E. (1994). Life cycle completed: A review. New York, NY: W. W. Norton. 
Etters, L., Goodall, D., \& Harrison, B. E. (2008). Caregiver burden among dementia patient caregivers: A review of the literature. Journal of the American Academy of Nurse Practitioners, 20(8), 423428.

Farran, C. J., Miller, B. H., Kaufman, J. E., \& Davis, L. (1997). Race, finding meaning, and caregiver distress. Journal of Aging and Health, 9(3), 316-333.

Ferketich, S. (1991). Focus on psychometrics: Aspects of item analysis. Research in Nursing and Health, 14, 165-168.

Fisher, G. G., Franks, M. M., Plassman, B. L., Brown, S. L., Potter, G. G., Llewellyn, D., ... \& Langa K. M. (2011). Caring for individuals with dementia and cognitive impairment: Findings from the aging, demographics, and memory study. Journal of the American Geriatrics Society, 59(3), 488-494.

Flynn Longmire, C. V., \& Knight, B. G. (2010). Confirmatory factor analysis of the Center for Epidemiologic Studies-Depression Scale in black and white dementia caregivers. Aging \& Mental Health, 14(8), 962-970.

Gaugler, J. E., Mittelman, M. S., Hepburn, K., \& Newcomer, R. (2010). Clinically significant changes in burden and depression among dementia caregivers following nursing home admission. BMC Medicine, 17;8:85. doi: 10.1186/1741-7015-8-85

Greenberg, P. E., Kessler, R. C., Birnbaum, H. G., Leong, S. A., Lowe, S. W., Berglund, P. A., \& Corey-Lisle, P. K. (2003). The economic burden of depression in the United States: How did it change between 1900 and 2000? Journal of Clinical Psychiatry, 64(12), 1465-1475.

Hair, J. F., Anderson, R. E., Tatham, R. L., \& Black, W. C. (1998). Multivariate data analysis (5th ed.). Upper Saddle River, NJ: Prentice Hall.

Haley, W., Gitlin, L., Wisniewski, S., Mahoney, D., Coon, D., Winter, L., ... \& Ory, M. (2004). Well-being, appraisal, and coping in African-American and Caucasian dementia caregivers: Findings from the REACH study. Aging \& Mental Health, 8(4), 316-329.

Haley, W. E., Roth, D. L., Coleton, M. I., Ford, G. R., West, C. A., Collins, R. P., \& Isobe, T. L. (1996). Appraisal, coping, and social support as mediators of well being in Black and White family caregivers of patients with Alzheimer's disease. Journal of Consulting and Clinical Psychology, 64(1), 121-129.

Haley, W. E., West, C. A., Wadley, V. G., Ford, G. R., White, F. A., Barrett, J. J., Harrell, L. E., \& Roth, D. L. (1995). Psychological, social, and health impact of caregiving: A comparison of Black and White dementia caregivers and noncaregivers. Psychology and Aging, 10(4), 540-552.

Janevic, M. R., \& Connell, C. M. (2001). Racial, ethnic, and cultural differences in the dementia caregiving experience: Recent findings. Gerontologist, 41(3), 334-347.

Joling, K. J., van Hout, H. P. J., Schellevis, F. G., van der Horst, H. E., Scheltens, P., Knol, D. L., \& van Marwijk, H. W. J. (2010). Incidence of depression and anxiety in the spouses of patients with dementia: A naturalistic cohort study of recorded morbidity with a 6-year follow-up. The American Journal of Geriatric Psychiatry, 18(2), 146-53. Retrieved from http://search. proquest.com/docview/195988062?accountid $=100$

Katon, W. J. (2003). Clinical and health services relationships between major depression, depressive symptoms, and general medical illness. Biological Psychiatry, 54(3), 216-226. doi: 10.1016/S0006-3223(03)00273-7

Knight, B. G., Fox, L. S., \& Chou, C. (2000). Factor structure of the burden interview. Journal of Clinical Geropsychology, 6(4), 249-258.

Lawton, M. P., Rajagopal, D., Brody, E., \& Kleban, M. H. (1992). The dynamics of caregiving for a demented elder among black and white families. Journal of Gerontology, 47(4), S156-S164. 
Marks, N. F., Lambert, J. D., \& Choi, H. (2002). Transitions to caregiving, gender, and psychological wellbeing: A prospective U.S. national study. Journal of Marriage and Family, 64(3), 657-667.

Nunnally, J. C., \& Bernstein, I. H. (1994). Psychometric theory (3rd ed.). New York, NY: McGraw-Hill.

Pinquart, M., \& Sorensen, S. (2004). Associations of caregiver stressors and uplifts with subjective wellbeing and depressive mood: A meta-analytic comparison. Aging \& Mental Health, 8(5), 438449.

Pratt, L. A., \& Brody, D. J. (2008). Depression in the United States household population, 2005-2006. National Center for Health Statistics Brief, 7, 1-7.

Radoff, L. S. (1977). The CES-D scale: A self-report depression scale for research in the general population. Applied Psychological Measurement, 1, 385-401.

Rosness, T., Mjørud, M., \& Engedal, K. (2011). Quality of life and depression in carers of patients with early onset dementia. Aging \& Mental Health, 15(3), 299-306. doi: $10.1080 / 13607861003713224$

Rush, A. J., \& Beck, A. T. (2000). Cognitive therapy. In H. J. Kaplan \& B. J. Sadock (Eds.), Comprehensive textbook of psychiatry (7th ed., pp. 2167-2178). Baltimore: Williams \& Wilkins.

Sheikh, J. I., \& Yesavage, J. A. (1986). Geriatric Depression Scale (GDS): Recent evidence and development of a shorter version. Clinical Gerontology, 5(1/2), 165-173.

Steptoe, A. (2007). Depression and physical illness. New York, NY: Cambridge University Press.

Strickland, O. L. (2003). Using factor analysis for validity assessment: Practical considerations [Editorial]. Journal of Nursing Measurement, 11(3), 203-205.

Tabachnick, B. G., \& Fidell, L. S. (2001). Using multivariate statistics. Boston, MA: Allen and Bacon.

Teschendorf, B., Schwartz, C., Ferrans, C. E., O'Mara, A., Novotny, P., \& Sloan, J. (2007). Caregiver role stress: When families become providers. Cancer Control: Journal of the Moffitt Cancer Center, 14(2), 183-189.

Thompson, E. H., Jr., Futterman, A. M., Gallagher-Thompson, D., Rose, A. M., \& Lovett, S. B. (1993). Social support and caregiving burden in family caregivers of frail elders. Journal of Gerontology, 48, 245-254.

Tremont, G. (2011). Family caregiving in dementia. Medicine \& Health, 94(2), 36-38.

Välimäki, T., Vehviläinen-Julkunen, K., Pietilä, A., \& Pirttilä, T. (2009). Caregiver depression is associated with a low sense of coherence and health-related quality of life. Aging \& Mental Health, 13(6), 799-807. doi: 10.1080/ 13607860903046487

Wang, Y. N., Shyu, Y. I., Chen, M. C., \& Yang, P. S. (2011). Reconciling work and family caregiving among adult-child family caregivers of older people with dementia: Effects on role strain and depressive symptoms. Journal of Advanced Nursing 67(4), 829-840.

Watson, L. C., Lewis, C. L., Moore, C. G., \& Jeste, D. V. (2011). Perceptions of depression among dementia caregivers: Findings from the CATIE-AD trial. International Journal of Geriatric Psychiatry, 26(4), 397-402. doi: 10.1002/gps.2539

Wong, P., Cheung, G., Fung, R., Koo, S., Sit, E., Pun, S., \& Au, A. (2008). Patient and caregiver characteristics associated with depression in dementia caregivers. Journal of Psychology in Chinese Societies, 9(2), 195-224.

Zarit, S. H., Reever, K. E., \& Bach-Peterson, J. (1980). Relatives of the impaired elderly: Correlates of feelings of burden. Gerontologist, 20(6), 649-655.

Zauszniewski, J. A. (1995). Development and testing of a measure of depressive cognitions in older adults. Journal of Nursing Measurement, 3(1), 31-41.

Zauszniewski, J. A. (1997). The Depressive Cognition Scale: Further psychometric evaluation. Journal of Nursing Measurement, 5(2), 191-200. 
Zauszniewski, J. A. (2006). Resourcefulness. In J. J. Fitzpatrick \& M. Wallace (Eds.), Encyclopedia of nursing research (pp. 256-258). New York, NY: Springer.

Zauszniewski, J. A., \& Bekhet, A. K. (2012). Developing a screening measure for early detection of depressive symptoms: The Depressive Cognition Scale. Western Journal of Nursing Research, 34(2), 228-242.

Zauszniewski, J. A., Chung, C., Krafcik, K., \& Sousa, V. (2001). Psychometric testing of the Depressive Cognition Scale in women with type 2 diabetes. Journal of Nursing Measurement, 9(1), 61-72.

Zauszniewski, J. A., Lai, C. Y., \& Tithiphontumrong, S. (2006). Development and testing of the Resourcefulness Scale for Older Adults. Journal of Nursing Measurement, 14(1), 57-68.

Zauszniewski, J. A., Picot, S. J. F., Debanne, S., Wykle, M., \& Roberts, B. L. (2002). Psychometric characteristics of the Depressive Cognition Scale in African American women. Journal of Nursing Measurement, 10(2), 83-95.

Zauszniewski, J. A., \& Suresky, M. J. (2010). Psychometric testing of the Depressive Cognition Scale in women family members of seriously mentally ill adults. Issues in Mental Health Nursing, 31(7), 483-490. 